\title{
DIETARY FATTY ACIDS WITH TRANS UNSATURATION
}

\author{
MICHAEL I. GURR
}

Maypole Scientific Services, Vale View Cottage, St Mary's, Isles of Scilly, TR21 0NU, United Kingdom

\section{CONTENTS}

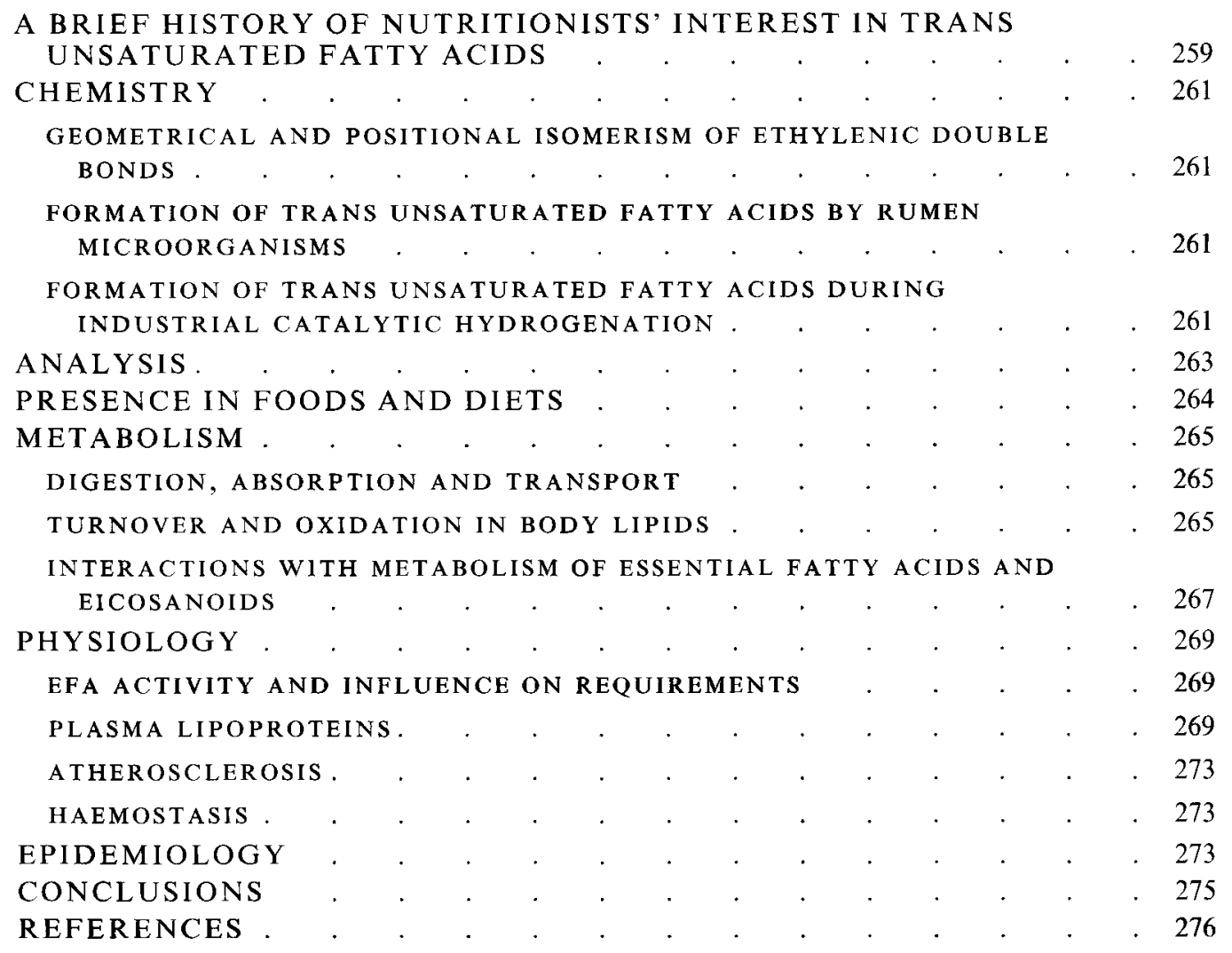

\section{A BRIEF HISTORY OF NUTRITIONISTS' INTEREST IN TRANS UNSA TURATED FATTY ACIDS}

Even a decade ago the term 'trans unsaturated fatty acids' (TFA) would have been familiar only to biochemists, lipid technologists and a handful of nutritionists. Today most nutritionists and many health conscious laymen will be aware of trans fatty acids (as they are now normally abbreviated: wrongly, as it happens, since it is the double bond - the unsaturation - not the fatty acid that can be 'trans'; some fatty acids contain cis and trans double bonds in the same molecule). 
As a lipid biochemist and also a one-time employee of Unilever Ltd, I was aware early in my career of the widespread occurrence of these substances and once studied the biosynthesis of the trans-3-hexadecenoic acid that is a universal and apparently obligatory constituent of the phosphatidylglycerol located in the chloroplast membranes of higher plants (Gurr \& Harwood, 1992). Biochemists are also aware that a trans-unsaturated fatty acid is an intermediate at each turn of the cycle of fatty acid biosynthesis in almost all organisms (Gurr \& Harwood, 1992). These examples, as well as the occurrence of TFA in ruminant tissues, should serve to debunk the now widespread misconception that fatty acids with trans unsaturation are 'unnatural'. In tung oil (from the Chinese plant Aleurities fordii) eleostearic acid $(9 c, 11 t, 13 t-18: 3)$ comprises $69 \%$ of the total fatty acids (Gunstone et al. 1994).

Regarding human nutrition, few people thought that fatty acids were particularly interesting until the discovery of the essential fatty acids (Burr \& Burr, 1929). There followed a great many investigations in which different fatty acids were tested for their essential fatty acid (EFA) activity. It was clear that TFA (at least the ones tested at that time) did not possess such activity and once more interest waned. (Much later columbinic acid, a fatty acid with the structure $5 t, 9 c, 12 c-18: 3^{*}$ found in columbine (Aquilegia vulgaris) seed oil, was found to possess EFA activity but this is merely an interesting oddity).

In 1982 I was requested, as a member of the Fat Evaluation Committee of the International Union of Nutritional Sciences (IUNS), to write a review on the metabolic and nutritional significance of the TFA. That review was never published by IUNS, so I offered it to the International Dairy Federation (Gurr, 1983). In the light of what has happened in TFA research over the past 10 years or so, its main interest is possibly the protocol I suggested for the biological assessment of TFA (see table 6 in Gurr, 1983), which has not been published elsewhere. In the report of the Committee on Medical Aspects of Food Policy (COMA) the comments and recommendations on TFA (Department of Health and Social Security, 1984) created an interest in TFA at a public health level that had not existed before.

The British Nutrition Foundation (BNF) established a Task Force on TFA and published their findings in 1987 (British Nutrition Foundation, 1987). An aspect that had most interested COMA, namely the effects of TFA consumption on plasma lipids and lipoproteins and on atherosclerosis, had been poorly researched and results were inconclusive. Interest revived when Mensink \& Katan (1990) showed that dietary TFA effectively raised low density lipoprotein cholesterol (LDL-C) and lowered high density lipoprotein cholesterol (HDL-C), thereby increasing the risk (according to conventional thinking) of coronary heart disease (CHD). In the first half of this decade there has followed a flurry of activity in researching metabolic, nutritional and health aspects of TFA with experimental and epidemiological techniques. The emphasis has been firmly on man in contrast to earlier work that was overwhelmingly concerned with experimental animals. So great had the interest become, that the BNF produced an updated Task Force report in 1995 (British Nutrition Foundation, 1995).

The literature before 1990 has been well reviewed (Beare-Rogers, 1983; Kritchevsky, 1983; Emken, 1984; Federation of American Societies for Experimental Biology, 1985; British Nutrition Foundation, 1987). Reviews since 1990 include those by Wahle \& James 1993; Kris-Etherton et al. 1995; Stender et al. 1995). The review by Kris-Etherton et al. is a particularly thorough appraisal of all aspects of TFA but not without controvery, as

Footnote: In the shorthand system for naming fatty acids, the number before the colon indicates the carbon chain length and that after the colon the number of double bonds. The geometrical configuration of a double bond is indicated by $c, t$ for $c i s$ and trans respectively, the convention generally used by those in the biological sciences. The convention used in chemistry designates these as $Z$ and $E$ respectively. 
indicated by some commentaries in the same issue of the journal. The purpose of this review is threefold: to present a succinct summary of technical aspects of TFA for the general reader (structure, analysis, content in foods); to review developments in metabolic and health aspects of TFA over the past five years or so; and to present a personal assessment of the state of the art and the significance of TFA in relation to current public health issues.

\section{CHEMISTRY}

\section{GEOMETRICAL AND POSITIONAL ISOMERISM OF ETHYLENIC DOUBLE BONDS}

When two adjacent carbon atoms in a fatty acid hydrocarbon chain are linked by an ethylenic double bond, the bond can have either cis $(Z)$ or trans $(E)$ geometry (geometric isomerism). The geometrical configuration (Fig. 1) has a profound effect on the spacial conformation of fatty acids. Molecules containing trans unsaturation can pack together more closely than their corresponding cis-isomers. Thus, the melting points of stearic $(18: 0)$, elaidic $(9 t-18: 1)$ and oleic $(9 \mathcal{c}-18: 1)$ acids are $69 \cdot 6,44 \cdot 0$ and $13 \cdot 2^{\circ} \mathrm{C}$ respectively and the melting properties of the acylglycerols in which such fatty acids are esterified in edible oils are similarly affected. Further details of the molecular conformation adopted by TFA can be found in the review by Kris-Etherton et al. (1995).

Naturally occurring unsaturated fatty acids also exhibit positional as well as geometrical isomerism, when the double bonds occur in different positions along the chain in fatty acids with otherwise identical empirical formulae. A well known and important example is the positional isomerism of linolenic acid giving rise to two naturally occurring positional isomers with distinctive biological properties : alpha-linolenic $(9 c, 12 c, 15 c-18: 3)$ and gammalinolenic $(6 c, 9 c, 12 c-18: 3)$ acids (Fig. 1). TFA are present in biological and food lipids as mixtures of positional isomers (Table 1).

\section{FORMATION OF TRANS UNSATURATED FATTY ACIDS BY RUMEN MICROORGANISMS}

Although the lipid in the diet of ruminants is rich in the polyunsaturated fatty acids linoleic and linolenic acids, the storage triacylglycerols of these species contain only small quantities of these fatty acids. Biohydrogenation takes place in the rumen, catalysed by enzymes in a variety of symbiotic anaerobic bacteria. During biohydrogenation, the cis double bonds in the dietary fatty acids are isomerized to the trans configuration and, at the same time, migration of double bonds also occurs, giving rise to a wide range of positional and geometrical isomers (Table 1). Trans double bonds occur in positions 3-16 (Parodi, 1976a; Craig-Schmidt, 1992). The predominant trans isomer is trans-vaccenic acid (11t18:1) while the only cis-isomer present in significant amounts is the one with the double bond in position 9. Small concentrations (c. 0.5-1.0\%) of cis, trans- and trans, trans-dienoic acids are also present. The total concentration of TFA in bovine fat ranges from 2 to $7 \%$ depending on breed, climate and feed.

\section{FORMATION OF TRANS UNSATURATED FATTY ACIDS BY INDUSTRIAL CATALYTIC HYDROGENATION}

Highly unsaturated acylglycerols in some seed and fish oils are unsuitable for many food uses because of their low melting points and susceptibility to peroxidation. Catalytic hydrogenation (hardening) is a means of increasing the solid fat content and melting point 
Geometrical isomers

(a)

$$
\begin{gathered}
\mathrm{CH}_{3}\left(\mathrm{CH}_{2}\right)_{7}-\mathrm{C}=\mathrm{C}-\left(\mathrm{CH}_{2}\right)_{7} \mathrm{COOH} \\
\mathrm{H}-\mathrm{H}
\end{gathered}
$$

9-cis-octadecenoic acid; oleic acid ; $9 c-18: 1(n-9)$.

(b)

$$
\begin{aligned}
\mathrm{CH}_{3}\left(\mathrm{CH}_{2}\right)_{7} & -\mathrm{C}=\mathrm{C} \\
\mathrm{H} & -\mathrm{H} \\
& >\left(\mathrm{CH}_{2}\right)_{7} \mathrm{COOH}
\end{aligned}
$$

9-trans-octadecenoic acid; elaidic acid; $9 t-18: 1(n-9)$

Positional isomers

(c) $\mathrm{CH}_{3}\left(\mathrm{CH}_{2}\right)_{4} \mathrm{CH}=\mathrm{CHCH}_{2} \mathrm{CH}=\mathrm{CHCH}_{2} \mathrm{CH}=\mathrm{CH}\left(\mathrm{CH}_{2}\right)_{4} \mathrm{COOH}$ all-cis-6,9,12-octadecatrienoic acid [gamma-linolenic acid ; $6 c, 9 c, 12 c-18: 3(n-6)$ ].

(d) $\mathrm{CH}_{3} \mathrm{CH}_{2} \mathrm{CH}=\mathrm{CHCH}_{2} \mathrm{CH}=\mathrm{CHCH}_{2} \mathrm{CH}=\mathrm{CH}\left(\mathrm{CH}_{2}\right)_{7} \mathrm{COOH}$ all-cis-9, 12,15-octadecatrienoic acid [alpha-linolenic acid; $9 c, 12 c, 15 c-18: 3(n-3)$ ].

Fig. 1. Geometrical and positional isomerism in fatty acids.

\begin{tabular}{|c|c|c|c|c|c|c|c|c|c|c|}
\hline \multirow[b]{2}{*}{ Product } & \multirow{2}{*}{$\begin{array}{l}\text { Total } \\
\text { TFA } \\
\text { g/100 g } \\
\text { fatty } \\
\text { acids }\end{array}$} & \multicolumn{9}{|c|}{ Position of double bond and \% of isomer } \\
\hline & & 6 & 7 & 8 & 9 & 10 & 11 & 12 & 13 & 14 \\
\hline Margarine & $16 \cdot 4$ & $1 \cdot 2$ & $3 \cdot 2$ & $10 \cdot 7$ & $22 \cdot 3$ & $22 \cdot 2$ & $18 \cdot 5$ & $11 \cdot 9$ & $6 \cdot 7$ & $3 \cdot 3$ \\
\hline Butter & $4 \cdot 3-7 \cdot 6$ & $0 \cdot 3$ & 0.3 & $1 \cdot 3$ & $8 \cdot 8$ & $5 \cdot 5$ & $60 \cdot 5$ & $4 \cdot 1$ & $4 \cdot 4$ & $5 \cdot 2$ \\
\hline
\end{tabular}

Table 1. Positional distribution of trans double bonds in butter and margarine

Data from Parodi $(1976 a, b)$. The margarine was described as a 'Table margarine' and was one of four products analysed, each with a slightly different distribution of positional isomers and total trans contents ranging from $4.2-23.9 \%$ of total fatty acids. The range of trans content of the butter sample represents normal seasonal variation. The important point to bring out is not the precise values for individual isomers but the contrast between the sharp peak at position 11 for butter and the rather broad distribution for all margarines. Very similar values are presented for more recent analyses in Kris-Etherton et al. (1995).

by reducing the total degree of unsaturation. Hydrogenation is normally carried out in an enclosed tank in the presence of hydrogen gas and a nickel catalyst at a temperature of about $180^{\circ} \mathrm{C}$. In the course of the reaction, which is never taken to completion, a proportion of the cis double bonds in the raw material is isomerized to trans bonds and there is also migration of both cis and trans bonds along the chain. The final mixture of isomers generated from seed oils is qualitatively similar to that produced by biohydrogenation in ruminants, although there are quantitative differences (Table 1). Unlike ruminant fat, no single trans isomer predominates: in many products there are approximately equal amounts of the trans isomers with double bonds in positions 8, 9, 10, 11 and 12 (Parodi, 1976b; Craig-Schmidt, 1992). There can be considerable differences in the isomer distribution between products (Parodi, 1976b). A small proportion (c. 3\%, range $0 \cdot 1-7 \cdot 5 \%$ ) of cis,trans-dienoic 18 carbon acids is usually present (Kris-Etherton et al. 1995). Such products would once have contained a small amount of the trans,trans-isomer 
but improvements in catalysts have essentially eliminated this component. The biological significance of this fact is discussed in a later section.

These remarks apply to the majority of oils that contain predominantly 18 carbon polyunsaturated fatty acids (PUFA). When manufacturers use fish oils with a high proportion of 20 and 22 carbon acids containing up to six double bonds, the opportunities for isomerism are clearly greater and the resulting mixtures of cis and trans positional isomers more complex.

\section{ANALYSIS}

Analytical information on TFA may be required by manufacturers (product composition) or research workers (composition in foods and biological tissues). Their needs are likely to be different, the research scientist requiring detailed information on all isomers present, the food manufacturer normally needing an overall figure for total trans bond content. The analytical approaches are also different. Readers will find a comprehensive discussion of the topic in the review by Firestone \& Sheppard (1992). There is currently no simple method that can satisfy the demands of both the research scientist and the food manufacturer with confidence but three promising developments will be indicated here.

\section{Fourier transform infrared spectroscopy}

All methods are based on the absorbance of isolated trans double bonds at $967 \mathrm{~cm}^{-1}$ but the Fourier transform method (FTIR) uses computing techniques to calculate and subtract a true baseline in the trans region derived from a similar zero-trans sample. Partial least squares analysis can also be applied to increase sensitivity so that the method can now analyse accurately trans monoenes at concentrations of less than $2 \%$ in the sample (Christie, 1995a). The method is much less accurate in analysing trans polyenes but this may not be a big drawback when analysing total trans content of product samples that have a low polyene content.

\section{Gas-liquid chromatography}

While gas-liquid chromatography (GLC) employing polar capillary columns is probably the most widely used method in research and quality control laboratories alike, the difficulties are considerable and perhaps not sufficiently widely recognized. The main problem is overlap between cis and trans isomers and this is particularly acute in chromatograms of hardened fats such as fish oils, containing highly unsaturated acids. No technical improvement is currently on the horizon that will afford complete separation of cis and trans isomers (Christie, 1995a). Combination of GLC and FTIR offers further flexibility (Ratnayake et al. 1990; Mossoba et al. 1993) but the degree of interpretive skill required makes the use of these methods problematical for routine analysis.

\section{Silver ion chromatography}

This technique offers the best potential for the complete and accurate analysis of complex isomeric mixtures, especially for monoenes. The principle is that the migration of lipids containing ethylenic double bonds on a silica gel stationary phase impregnated with silver ions is retarded: the more unsaturation, the slower the migration. A monoene with trans geometry is less retarded than the corresponding cis-monoene. Silver ion high performance liquid chromatography (HPLC) is simple, clean, rapid, gives good resolution and is amenable to automation for routine use (Toschi et al. 1993; Adlof et al. 1995). Potential improvements can be achieved by using derivatives of fatty acids other than methyl esters (Christie, 1995a,b). 
Table 2. Estimated intakes of dietary $T F A$ in several countries $(g / d)$

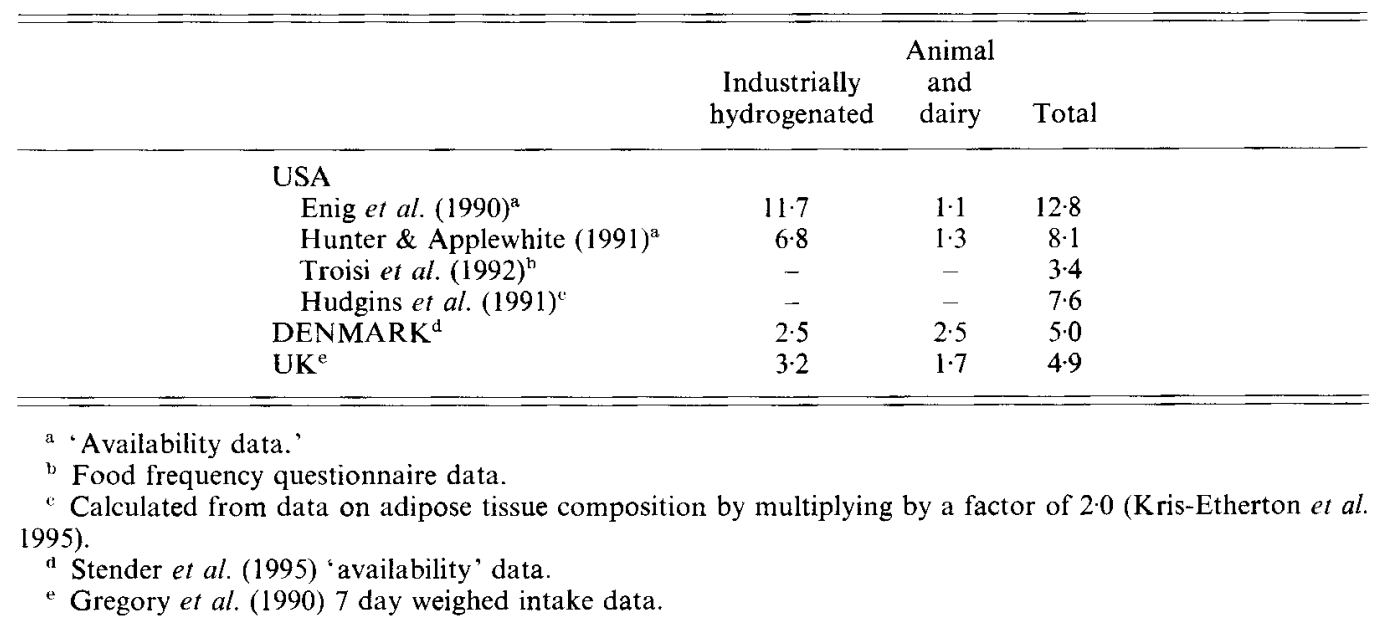

At present, TFA determination requires a skilled analyst with considerable interpretive ability (Christie, 1995a). It will be some time before methods have evolved that allow routine analysis of complex mixtures by relatively unskilled personnel with confidence. These remarks are relevant to the interpretation of many of the metabolic, epidemiological and nutritional studies discussed later.

\section{PRESENCE IN FOODS AND DIETS}

For up-to-date information on dietary TFA in the UK, the reader should consult the most recent BNF Task Force Report (British Nutrition Foundation, 1995). Relevant information for other countries is indicated in Table 2.

In the UK, average daily intakes of TFA in 1994 were estimated to be 4-6 g per person, representing about $6 \%$ of dietary fat and $2 \%$ of dietary energy. Individuals in the top $2.5 \%$ of the intake distribution may be consuming $12 \mathrm{~g}$ or more, whereas those in the lowest $2.5 \%$ of the distribution may consume only $1-2 \mathrm{~g} / \mathrm{d}$. Of these, $34 \%$ comes from fats of ruminant origin and over $60 \%$ from foods incorporating industrially hardened fats. An extremely small intake comes from other natural sources such as the lipids in plant foods and the fats of non-ruminants that have incorporated TFA into their lipids from their diets.

There was a significant fall in the total TFA in the average British diet between 1980 and 1994. A large part of this trend was contributed by decreases in consumption of some products whose TFA content, nevertheless, remained the same (e.g. butter) and by decreases in the TFA content of some foods whose total consumption either did not change or increased (e.g. soft margarines not rich in PUFA). The latter has occurred because manufacturers have reformulated a number of products in response to unease about TFA levels in foods. Other minor contributors to lower figures for TFA consumption have been better analytical techniques which have tended to give lower values than older techniques and the availability of information on a wider range of products. 


\section{METABOLISM}

\section{DIGESTION, ABSORPTION AND TRANSPORT}

According to evidence presented in the reviews cited above, it can be concluded that the digestion, absorption and transport as lipoproteins of lipids containing TFA or their cis counterparts do not differ significantly (Fig. 2). When there have been differences it is because factors such as chain length were not properly controlled. Thus hydrogenation of fish oils yields cis and trans isomers with C20 and C22 chain lengths, which are less efficiently digested and absorbed irrespective of the nature of the double bonds. This view, gained from experiments with laboratory animals and from miscellaneous studies in vitro, has been supported by the work of Emken and colleagues (Adlof \& Emken, 1986; Emken et al. 1980, 1986, 1987, 1989). These research workers gave human subjects meals that incorporated synthetic triacylglycerols labelled with deuterated trans isomers of $18: 1$ and $12 c, 15 t-18: 2$. Time courses of incorporation of these isomers into, and their disappearance from, chylomicron triacylglycerols were compared with those of similar dietary triacylglycerols labelled with deuterated saturated fatty acids (SFA), cis isomers of 18:1 and $9 c, 12 c-18: 2$. These experiments revealed few differences between TFA and other fatty acids in respect of their incorporation and disappearance from the transport lipoproteins.

\section{TURNOVER AND OXIDATION IN BODY LIPIDS}

Dietary TFA are incorporated into all the major types of complex lipids in most human tissues. The concentration in adipose tissue triacylglycerols is roughly proportional to the dietary concentration and is now frequently used as a measure of relative dietary intakes (Katan et al. 1986; Hudgins et al. 1991; Aro et al. 1995; Kris-Etherton et al. 1995; Roberts et al. 1995). Triacylglycerol TFA are mainly esterified in positions 1 and 3. In other tissues, such as heart, liver or brain, TFA occur predominantly in membrane phospholipids, where they are preferentially esterified in position 1 . This specificity also applies to human plasma phospholipids (Adlof \& Emken, 1986; Emken et al. 1980, 1986, 1987, 1989). Complete positional specificity is rarely observed, since the positional distribution in phospholipids may also be influenced by double bond position (Wood, 1979) and the level of EFA in the diet (Hill et al. 1979; Zevenbergen et al. 1988). Poor incorporation of TFA into plasma cholesteryl esters, reported by Emken et al. $(1980,1986,1987)$, may be explained on the basis that TFA are largely excluded from position 2 of phosphatidylcholine, which is the donor of the fatty acid for the esterification of cholesterol in plasma.

Labelling of triacylglycerols in human plasma with deuterated TFA reached a peak $2-6 \mathrm{~h}$ after ingestion and most of the label had been eliminated by $24 \mathrm{~h}$ (Emken et al. 1980, 1986, 1987). Phospholipid labelling reached a peak 6-8 $\mathrm{h}$ after ingestion and most of the label had been lost by $48 \mathrm{~h}$. Information about metabolism of TFA in other tissues and organs is available mainly from animals. After giving rats a diet containing $15 \%$ by weight of fat, of which 50\% was TFA, trans-18:1 was found primarily in phospholipids and triacylglycerols of plasma, liver, kidney, heart, adipose tissue and erythrocytes (Moore et al. 1980). Eight weeks after changing to a diet that contained no TFA, negligible amounts of TFA remained in these tissues, demonstrating the ready catabolism of TFA and their removal from tissues.

Few studies have compared rates of oxidation of TFA with either their cis-counterparts or SFA in vivo. There is little evidence from animal experiments for important differences (British Nutrition Foundation, 1995). Human studies with labelled TFA were not designed to provide evidence for total oxidative breakdown of TFA but did provide evidence about limited chain shortening (Emken et al. 1980, 1986, 1987). Formation of the isomer two 


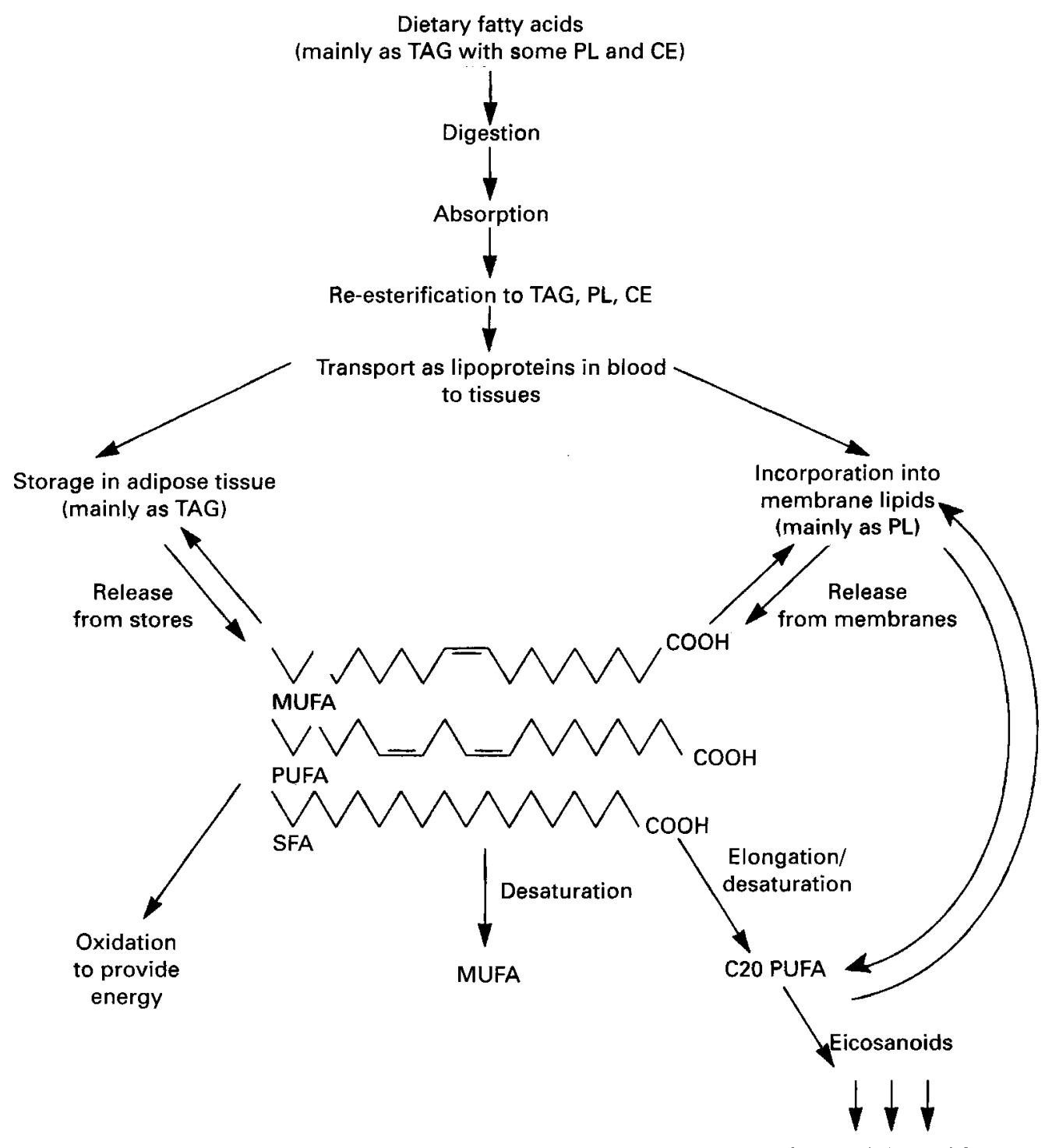

Specific physiological functions

Fig. 2. Metabolic fates of fatty acids: TAG, triacylglycerols; PL, phospholipids; CE, cholesteryl esters; MUFA, monounsaturated fatty acids; PUFA, polyunsaturated fatty acids; SFA, saturated fatty acids. Reproduced from British Nutrition Foundation (1995) with kind permission of the British Nutrition Foundation.

carbon atoms shorter than $11 t$-18:1 (i.e. $9 t$-16:1) appeared to be two to three times greater than for $7 c-16: 1$ formed from $9 c-18: 1$ but the extent of the conversion was very small $(0 \cdot 2-0.3 \%)$. There was no evidence for chain shortening of other isomers.

Studies with isolated mitochondria or other preparations in vitro have to be interpreted cautiously since different substrates may not be presented in exactly the same form because of their different physical properties, and oxidation rates in vitro may not truly reflect rates in vivo. Homogenates of human cardiac tissue oxidized $9 c-18: 1$ and $9 t-18: 1$ at a similar rate. Using another approach, Zevenbergen et al. (1988) found no impairment of oxidative 
function in mitochondrial preparations in vitro from rats that had been given a diet containing $20 \%$ dietary energy as trans-18: 1 even in the presence of only $0.4 \%$ energy as linoleic acid.

\section{INTERACTIONS WITH THE METABOLISM OF ESSENTIAL FATTY ACIDS AND EICOSANOIDS}

Several early observations suggested that when TFA were included in diets of animals whose intakes of EFA were marginal, the animals developed signs of EFA deficiency more rapidly than in their absence. These publications have been amply described in the reviews cited in the introductory section. Two main mechanisms have been invoked to explain these observations, namely that TFA (i) inhibit enzymes involved in the desaturation of linoleic or alpha-linolenic acids or (ii) compete with linoleic (or alpha-linolenic) acid in metabolic pathways.

\section{Inhibition of enzymes}

Information on the inhibition of desaturatases comes entirely from experiments with animals, mainly rats. Experiments were performed either by assaying desaturase activity in subcellular fractions isolated from tissues of animals given diets containing TFA or by observing changes in proportions of fatty acids in their tissues. Measurement of enzyme activities in vitro gives information about potential activities under optimum conditions and is not necessarily relevant to the overall outcome of complex metabolic transformations in vivo. The most potent inhibitor by far was $t, t-18: 2$, which is now a minor component of diets. Conclusions about desaturase activities drawn from simple observation of ratios of fatty acids in tissues are unreliable since so many competing reactions determine the ultimate tissue fatty acid composition.

There was no evidence for the desaturation of any of the deuterated substrates given to human subjects by Emken and colleagues (Adlof \& Emken, 1986; Emken et al. 1980, 1986, 1987 , 1989). However, only plasma lipids were analysed and to draw firm general conclusions it would have been necessary to analyse other tissues and organs. Koletzko (1992) studied the plasma lipids of 29 premature babies on the fourth day of life. He found an inverse association between the proportion of the long-chain elongation/desaturation products of linoleic and alpha-linolenic acids and the proportion of $t-18: 1$ in the triacylglycerols. The title of his paper ("TFA may impair biosynthesis of long chain polyunsaturates and growth in man') has excited great interest from a public health point of view but the evidence that the observed changes in composition were the result of impairment of EFA desaturation was indirect.

Inhibition of 5- and 6-desaturases by TFA has been demonstrated in human cells grown in culture (Rosenthal \& Whitehurst, 1983; Cook \& Emken, 1990). The 9t-18:1 was more effective than the $11 t-18: 1$ isomer and saturated acids were ineffective (Rosenthal \& Whitehurst, 1983). It is surprising that human cell cultures have not been more widely used in TFA research.

\section{Competition in metabolic pathways}

The same series of enzymes catalyses the elongation and further desaturation of the $n-6$ (linoleic) and $n-3$ (alpha-linolenic) families of PUFA. It is well established that the precursor fatty acids can compete for these enzymes so that the pattern of end products is determined by the relative activities of the enzymes towards their substrates and the proportions of the precursors available to the enzymes (Gurr \& Harwood, 1992). Oleic acid $(9 c-18: 1)$, the most common fatty acid in diets and in the body, can also compete in these 
pathways, although its initial desaturation by the 6-desaturase is slower than that of linoleic and linolenic acids. Thus, when the amount of linoleic acid in the diet is marginal and the amount of oleic abundant, the desaturation/elongation of oleic acid predominates, resulting in an accumulation of eicosatrienoic acid $(5 c, 8 c, 11 c-20: 3 n-9$, 'Mead acid') which is not normally detectable in tissues. The ratio of $20: 3 n-9$ to $20: 4 n-6$ (arachidonic acid) has frequently been used as a biochemical index of EFA deficiency since it is measurable in tissues before overt signs of deficiency are apparent, a ratio greater than 0.4 being normally accepted as indicating deficiency.

TFA can be substrates for desaturases, giving rise to PUFA with trans unsaturation (Ratnayake et al. 1994) but the isomers studied were not important components of human diets. Early work of Dhopeshwarkar \& Mead (1961) showed that rats given diets only marginally sufficient in EFA exhibited frank EFA deficiency if given $9 c-18: 1$ (oleic acid) as a fat supplement but not when the supplement was $9 t-18: 1$. This suggested that competition by $9 t-18: 1$ for the enzymes of EFA metabolism was weak. More recent research by Zevenbergen and colleagues (1988) has investigated interactions between dietary fatty acids when rats were given diets with $20 \%$ energy as $t-18: 1$ and graded inclusions of linoleic acid ranging from $0.4 \%$ to $7 \cdot 1 \%$ dietary energy. Controls received no TFA with either $2 \%$ or $5 \%$ energy as linoleic acid. In controls, Mead acid was absent when linoleic acid contributed $5 \%$ energy, and contributed $0.9 \%$ total fatty acids when linoleic acid was included at $2 \%$ energy. In the presence of TFA at $20 \%$ energy, Mead acid was present at $1 \%$ or less of total fatty acids when linoleic acid contributed $2 \%$ or more of dietary energy and increased to $4 \%$ total fatty acids at the lowest level of inclusion of linoleic acid. The presence of TFA led to a decrease in arachidonic acid in the phosphatidylcholines of liver mitochondria only at dietary linoleic acid levels of $2 \%$ or less but in phosphatidylethanolamines the proportion of arachidonic acid increased.

These carefully controlled experiments demonstrated minimal metabolic effects of high TFA inclusions as long as the diet contained $2 \%$ or more of dietary energy from linoleic acid. It is worth noting that rat tissues generally have higher desaturase activities than corresponding human tissues and it is possible that inhibitory or competitive effects of TFA could be greater in human tissues. This issue needs research. As against this, average intakes in the UK and several other countries are of the order of $2 \%$ of dietary energy, ten times less than the intakes studied in these rat experiments. The likelihood of overt or even covert effects on EFA metabolism in man, even at the highest recorded TFA intakes, is small unless individuals are consuming diets unusually low in linoleic acid content.

\section{Membrane function and eicosanoid metabolism}

There is no doubt that when biological membranes are presented with a mixture of fatty acids that contain TFA, the latter can be incorporated into the lipids of the membrane, whether they are taken up from the blood in vivo or from the bathing medium in cultured cells or model membrane preparations. In theory, changes in membrane fatty acid composition can influence the physical properties of the membrane and in turn the activities of membrane enzymes. In practice, few significant changes in membrane physical properties have been observed, either in studies in vitro (Seelig \& Waespe-Šarčevic̀, 1978) or in vivo (Benga et al. 1984). One explanation is that TFA are normally incorporated preferentially into position 1 of phospholipids replacing SFA, resulting in no overall significant change in physical properties. Much discussion of the potential physiological effects of TFA has been speculative and has failed to consider homeostasis, whereby perturbations to membranes result in subtle compensations that maintain membrane properties within workable limits. Complex organisms would clearly be at a distinct disadvantage if small dietary changes could severely and adversely affect membrane function. 
It has been speculated that one vital function that occurs in membranes and which might be influenced by TFA is eicosanoid formation from EFA. The activities of the cyclooxygenase and lipoxygenase enzymes might be influenced by a change in membrane physical properties or, as is more likely in view of the foregoing discussion, the products of those enzymes may be influenced by the pattern of substrates available to them.

No evidence has been forthcoming to support Holman's speculation that unusual PUFA arising from desaturation/elongation of dietary TFA could give rise to eicosanoids with unpredictable biological activities (Holman, 1985). Animal experiments that appeared to show significant effects of TFA on eicosanoid formation often involved large doses of isomers (such as $t, t-18: 2$ ) that are not important components of modern human diets, in the presence of very low levels of linoleic acid (e.g. see Hwang \& Kinsella, 1979). More recent work of Zevenbergen \& Haddeman (1989) found no influence of $t-18: 1$ at $20 \%$ of dietary energy on eicosanoid formation in rats as long as the diet contained $2 \%$ or more of energy as linoleic acid. No pathological, histological, clinical or haematological abnormalities were observed when rats were given $2 \%$ linoleic acid with $20 \%$ dietary energy as TFA.

To this reviewer's knowledge, there have been no systematic studies of the influence of TFA on eicosanoid production in man. In view of the vital importance of these compounds in human physiology, this might be a fruitful area of future research.

\section{PHYSIOLOGY}

\section{EFA ACTIVITY AND INFLUENCE ON REQUIREMENTS}

In general, TFA do not possess EFA activity. There is one known exception. Columbinic acid, mentioned in the introductory section, has no significance in human diets.

As discussed in the previous section, relatively high inclusions of TFA in animal diets in the presence of linoleic acid below about $2 \%$ of dietary energy can result in the presence of Mead acid in tissue lipids in detectable amounts and an increase in the ratio of 20:3 $n-9 / 20: 4 n-6$ that suggests mild covert EFA deficiency and, by implication, increased EFA requirements. Such conditions are unlikely to occur in human experience except in a few individuals with unusual diets, although clearly these cases should not be minimized or dismissed. The body pool of linoleic acid available to be converted into long chain PUFA is so large as to make significant interference by TFA unlikely even at relatively low ratios of dietary linoleic acid to TFA.

Furthermore, the physiological or pathological significance of a raised $20: 3 n-9 / 20: 4$ $n-6$ ratio without any overt signs of EFA deficiency is not understood. Until this question has been researched more thoroughly, it seems premature to place too much reliance on this ratio as a marker to assess EFA adequacy (Wahle \& James, 1993). Mead acid is present in the phospholipids of the umbilical cord artery of apparently normal human infants (Reddy et al. 1994) and this might be interpreted as indicating that covert EFA deficiency is normal during pregnancy. Why this should be and whether the phenomenon is more widespread needs further investigation.

\section{INFLUENCE ON PLASMA LIPOPROTEINS}

Human metabolic studies have been extensively reviewed (see Introduction) and the results have been summarized by the British Nutrition Foundation (1995) as follows. "There is a dose-response relationship which would indicate that, theoretically, each $1 \%$ increase in dietary energy from TFA at the expense of oleic acid will raise LDL cholesterol by 
approximately $0.040 \mathrm{mmol} / 1$ and decrease HDL by approximately $0.013 \mathrm{mmol} / 1$. Assuming no change in any other lipoprotein, this theoretically equates to an increase in total blood cholesterol of $0.027 \mathrm{mmol} / \mathrm{l}$. Since average LDL and HDL cholesterol concentrations in the UK are 4.7 and $1.2 \mathrm{mmol} / \mathrm{l}$, respectively, this would theoretically amount to a $0.99 \%$ increase in LDL and a $1.13 \%$ decrease in HDL cholesterol levels. TFA are qualitatively different to saturated fatty acids in their effects on HDL-cholesterol - saturated fatty acids raise HDL cholesterol while TFA lower it. TFA raise LDL cholesterol to approximately the same extent as do saturated fatty acids." These conclusions relate to the main published studies to 1994, namely: Mensink \& Katan, 1990; Mensink et al. 1992; Nestel et al. 1992; Zock \& Katan, 1992; Lichtenstein et al. 1993; Wood et al. 1993; Judd et al. 1994.

Few human metabolic studies reported specific effects of TFA on either plasma total triacylglycerols or very low density lipoproteins. In those observational studies that made appropriate measurements (reviewed by Kris-Etherton et al. 1995) there was no significant correlation between dietary consumption of TFA and plasma triacylglycerol concentration.

The concentration of lipoprotein (a) (Lp(a)) in plasma has been regarded by many as an independent risk marker for CHD, although this is not universally accepted (British Nutrition Foundation, 1995). Mensink et al. (1992) and Nestel et al. (1992) found that dietary trans isomers of 18:1 resulted in a small increase in Lp(a) compared with SFA. The effect was most marked in subjects who had the highest initial plasma Lp(a) concentrations. Neither Lichtenstein et al. (1993) nor Judd et al. (1994) found changes in Lp(a) as a result of giving dietary TFA. It would be wise to reserve judgment about the influence of TFA on $\mathrm{Lp}(\mathrm{a})$. Its concentration is not normally distributed in the population and the responses are markedly greater in those with the highest habitual concentrations. Moreover, widely different assays were used in the published studies and methods need to be standardized.

Designing an experiment to assess the influence of TFA on blood lipids is beset with problems because TFA in natural and processed fats are normally ill-defined and because changing the level of dietary TFA inevitably results in changes in levels of other fatty acids. Some of these have little influence on blood lipids (SFA with chain lengths up to C10 and of $\mathrm{C} 18$ and above); 18:2n-6 may have a significant effect depending on its dietary concentration; the influence of oleic acid is less predictable and still controversial (Grundy \& Denke, 1990; Hegsted et al. 1993).

Several questions need to be considered by those designing experiments and those hoping to interpret the results of publications.

(1) What is an appropriate level of dietary fat? Some studies have used a level representative of that in the community in which the study was conducted (frequently $40 \%$ of dietary energy); others have preferred to use lower fat inclusions that reflect 'dietary guidelines'. It has been assumed that it is important for the fat level to remain the same, whatever the level of TFA inclusion, but a different view is argued later.

(2) Which fatty acids will be exchanged by the TFA included in the experimental diet? Because of its hypocholesterolaemic effect, the level of linoleic acid should be held constant in all treatments that are compared. This was usually but not always so in the published studies. In practice, the appropriate comparison is with the SFA, since that is what TFArich fats normally replace. Some but not all of the published studies exchanged TFA for SFA, keeping cis-monounsaturates (MUFA) constant. Different sources of SFA will present different proportions of these acids that are cholesterol raising and 'neutral', so that the basis for comparison will alter. Many authors have exchanged TFA with cisMUFA. While this may have a certain scientific logic, it is not what happens in practical diets because of the differences in texture between fats and oils rich in cis-MUFA compared with those rich in TFA. Some critics have argued that when cis-MUFA are not held constant, it is impossible to distinguish whether effects are due to changing TFA or cis- 
Table 3. Comparison of serum lipid in human subjects given diets of different fatty acid composition in the study of Mensink \& Katan (1990)

\begin{tabular}{|c|c|c|c|}
\hline Diet group & $\begin{array}{c}\text { Total } \\
\text { cholesterol, } \\
\text { mmol/1 }\end{array}$ & $\begin{array}{c}\text { HDL } \\
\text { cholesterol, } \\
\text { mmol/l }\end{array}$ & $\begin{array}{c}\text { Triacylglycerol, } \\
\text { mmol/1 }\end{array}$ \\
\hline Pre-study & $\begin{array}{l}4 \cdot 75 \\
(3 \cdot 40-7 \cdot 15)\end{array}$ & $\begin{array}{l}1 \cdot 30 \\
(0 \cdot 63-2 \cdot 38)\end{array}$ & $\begin{array}{l}0.96 \\
(0.36-2.54)\end{array}$ \\
\hline $\begin{array}{l}\text { After } 3 \text { weeks on: } \\
\text { cis-monounsaturated } \\
\text { trans-monounsaturated } \\
\text { saturated }\end{array}$ & $\begin{array}{l}4.46(0.66) \\
4.72(0.72) \\
5.00(0.71)\end{array}$ & $\begin{array}{l}1.42(0.32) \\
1.25(0.29) \\
1.42(0.32)\end{array}$ & $\begin{array}{l}0.81(0.35) \\
0.94(0.40) \\
0.94(0.47)\end{array}$ \\
\hline
\end{tabular}

Combined values for 25 men and 34 women.

Mean (SD) $\mathrm{mmol} / \mathrm{l}$ for values after 3 weeks on the three experimental diets. Ranges of values recorded at baseline (i.e. 'pre-study' habitual diets). There was no control group maintained on the habitual diets for the three week study period. No values were presented for LDL at baseline.

MUFA, since the latter are regarded as hypocholesterolaemic (Applewhite, 1994). Arguments about the latter view have been well rehearsed (Grundy \& Denke, 1990; Hegsted et al. 1993). If oleic acid is hypocholesterolaemic, comparisons between oleic and TFA will exaggerate any hypercholesterolaemic effect of the latter.

This point is well illustrated by the work of Mensink \& Katan (1990). Comparisons between the oleic acid group, considered as the reference group, and the other two groups after three weeks revealed a $6 \%$ increase in plasma total cholesterol concentration in the 'TFA' group and a $12 \%$ increase in the 'SFA' group (Table 3). Comparisons between the total cholesterol values for the three dietary groups after 3 weeks and the initial 'baseline' values showed that the values had decreased $6.1 \%$ and $0.6 \%$ in the 'oleic' and 'TFA' groups respectively and increased by $5.3 \%$ in the 'SFA' group. It can be argued legitimately that such comparisons are invalid in the absence of a control group that had remained on the original diet for the three weeks of the experiment. Nevertheless, this appraisal underlines the need to take care when making comparisons with a 'reference' group and suggests that an additional control group maintained on a standardized baseline diet might be advantageous.

(3) What sources of TFA should be used? All food sources of TFA contain a mixture of trans (as well as cis) positional isomers. A truly scientific approach should employ a synthetic fat with a single trans isomer, since positional isomers and those with different chain lengths may have different biological effects. Human studies have not generally employed this approach, although the deuterated compounds used in the experiments of Emken and colleagues (Adlof \& Emken, 1986; Emken et al. 1980, 1986, 1987, 1989) were pure isomers. Mensink \& Katan (1990) compared a high oleic sunflower oil with a partly hydrogenated preparation made from the same oil. This ensured that the mixture was restricted to trans monoenes with 18 carbons but it would have contained a mixture of positional isomers.

Use of products containing partly hydrogenated fish oils increases the problems of interpretation since the long chain length influences metabolism independently of the presence of trans unsaturation. Most research into effects of TFA on blood lipids has concentrated on 18 carbon acids and the effects of longer chain lengths need further investigation.

(4) What amounts of TFA should be used? Mensink \& Katan's (1990) initial work used a TFA intake of $11 \%$ of dietary energy. Judd et al. (1994) criticized this level as being on 
the high side of normal intakes and used two levels of 3.8 and $6.6 \%$ dietary energy. If everyday foods are used, it is difficult to construct diets that have much less than $1-2 \%$ TFA. Several reviewers have constructed 'dose-response' curves based on the combined results from several different publications. Although it is said that there is a dose-response relationship between TFA intake over the range $1-11 \%$ of dietary energy and change in plasma LDL concentration, the relationship is far from convincing (Fig. 5.1 in British Nutrition Foundation, 1995).

(5) What is an appropriate starting point for the experiment and how long should it last? When subjects are recruited for a study, they have probably been consuming diets that differed widely in their content of TFA. In experiments involving addition of TFA to the diet, these differences are perpetuated and exaggerated since initially high consumers will then be receiving extremely high amounts. Some nutritionists have designed the experiment to include a 'run-in' period in which all subjects are given the same diet so that each subject starts from the same dietary base at the beginning of the 'treatment' period. This technique has not been employed in dietary studies with TFA. Most TFA studies have provided poor information about the dietary background of the participants. The length of time allocated to a study has to be a compromise between a sufficient time for lipoprotein concentrations to stabilize at their new levels and a period that is not so great that subjects no longer comply conscientiously with the restrictions imposed by the study. Katan and colleagues stated that lipoprotein levels stabilize after two weeks (Brussaard et al. 1982; Mensink \& Katan, 1990). All the main recent studies on TFA have employed periods of 3 weeks or more.

In summary, confidence in the now familiar conclusions that TFA raise plasma total and LDL-C but rather less than the cholesterol-raising SFA and also lower HDL-C is reduced because many experiments used an inappropriate basis for comparison and did not always control for other fatty acids that had demonstrated hypo- or hypercholesterolaemic effects. It is noteworthy that in experiments with hamsters, dietary $9 t-18: 1$, in contrast to $9 c-18: 1$, did not significantly alter the receptor activity, production rate or plasma concentration of LDL (Woollett et al. 1994).

It has been a matter of dogma that the proportion of dietary energy supplied by fat should be held constant because the fat: carbohydrate ratio influences plasma cholesterol concentrations independently of fatty acid composition (Beynen \& Katan, 1989). A recent publication has disputed this assertion and found that plasma total cholesterol, LDL-C and HDL-C concentrations were not different in subjects given isoenergetic diets that contained either 22 or $39 \%$ of energy as fat but whose fatty acid compositions were identical (Nelson et al. 1995). Consequently, a design that changed only the amount of TFA added to the diet, resulting in diets differing in the proportion of energy as fat but leaving the amounts of all other fatty acids exactly the same, should avoid many of the problems discussed here.

Metabolic studies are needed to answer the scientific question: how do individual fatty acids, or different fats and oils, influence plasma lipoprotein concentrations? But people do not normally live in metabolic units with artificial diets imposed upon them for limited periods and it is legitimate to ask the question how relevant are such studies to "real life'? If we compare plasma lipid concentrations in people consuming widely different amounts of TFA under normal living conditions for extended periods does this not provide a more realistic picture? It is notoriously difficult to assess TFA intakes reliably with the traditional techniques for measuring food and nutrient intakes (British Nutrition Foundation, 1995; Kris-Etherton et al. 1995). There is, nevertheless, general acceptance that concentrations present in adipose tissue provide an accurate assessment of relative habitual intakes even if they cannot provide an absolute figure for the amount consumed in $\mathrm{g} / \mathrm{d}$. One such study (Hudgins et al. 1991) found no correlation between TFA concentration in adipose tissue of 
76 men and any plasma lipoprotein fraction, suggesting that under normal conditions of life dietary TFA have no important influence on plasma lipids. This conclusion is consistent with more general evidence that dietary fatty acids explain only a small part of the variance in plasma lipids (Gurr et al. 1989; Gurr, 1992) whether intakes are assessed by adipose tissue analysis (Berry et al. 1986) or weighed intake methods (Fehily et al. 1988, 1993).

\section{ATHEROSCLEROSIS}

Interest in the effects of TFA on plasma lipoproteins is mainly because of the reputed links between the latter and atherosclerosis. There is no evidence from animal studies that TFA have any influence on the development of experimental atherosclerosis provided that the diet contains an adequate level of linoleic acid.

\section{HAEMOSTASIS}

There is no reliable scientific evidence that TFA influence either blood pressure or the blood coagulation system in living human beings.

\section{EPIDEMIOLOGY}

There have been seven major epidemiological studies published since 1990 that investigated a potential association between dietary TFA intakes and aspects of CHD. These are summarized in Table 4 and have been discussed in detail (British Nutrition Foundation, 1995; Kris-Etherton et al. 1995). The latter have also reviewed studies published before 1990.

The findings were inconsistent and any overall assessment needs to take into account the limitations of individual studies. These are principally the reliability of estimation of dietary intakes. Measurement of the TFA content of adipose tissue overcomes the many problems of retrospective assessment, over lengthy periods of time, of intakes by food frequency questionnaires and diet histories. Such problems are exacerbated by different and changing TFA contents of many food products. As discussed earlier, even modern capillary GLC has its limitations and the correct identification of trans isomers in adipose tissue should not necessarily be assumed. Another problem lies in assessing the relationship between adipose tissue TFA content and actual intake.

Confidence in the biological significance of statistical associations revealed in epidemiological studies is enhanced if a graded response to different doses of TFA can be demonstrated. In the publication by Ascherio et al. (1994), the authors stated in their abstract: " ... intake of TFA was directly related to risk of myocardial infarction (relative risk for highest compared with lowest quintile, $2 \cdot 44 ; 95 \%$ confidence interval, $1 \cdot 42,4 \cdot 19$; for trend $P<0.0001$ ). This relation remained highly significant after adjustment for established coronary risk factors, multivitamin use, and intake of saturated fat, monounsaturated fat, linoleic acid, dietary cholesterol, vitamins $\mathrm{E}$ and $\mathrm{C}$, carotene and fibre...". The authors omitted to point out that the corresponding comparison between the third and lowest quintiles of intake, when fully adjusted for confounding factors, gave a relative risk of 0.40 . Since the confidence intervals were $0 \cdot 19-0.83$, it is an equally valid conclusion that moderate levels of intake of TFA protected against myocardial infarction!

Only one study (Willett et al. 1993) was designed prospectively (Table 4). This large study (more than 80000 subjects followed for 8 years) has caused wide interest not only because it claimed that highest intakes of TFA were associated with a $50 \%$ increase in CHD but also that only TFA from industrially hydrogenated fats, not from ruminant fats, were 
M. I. GUR R

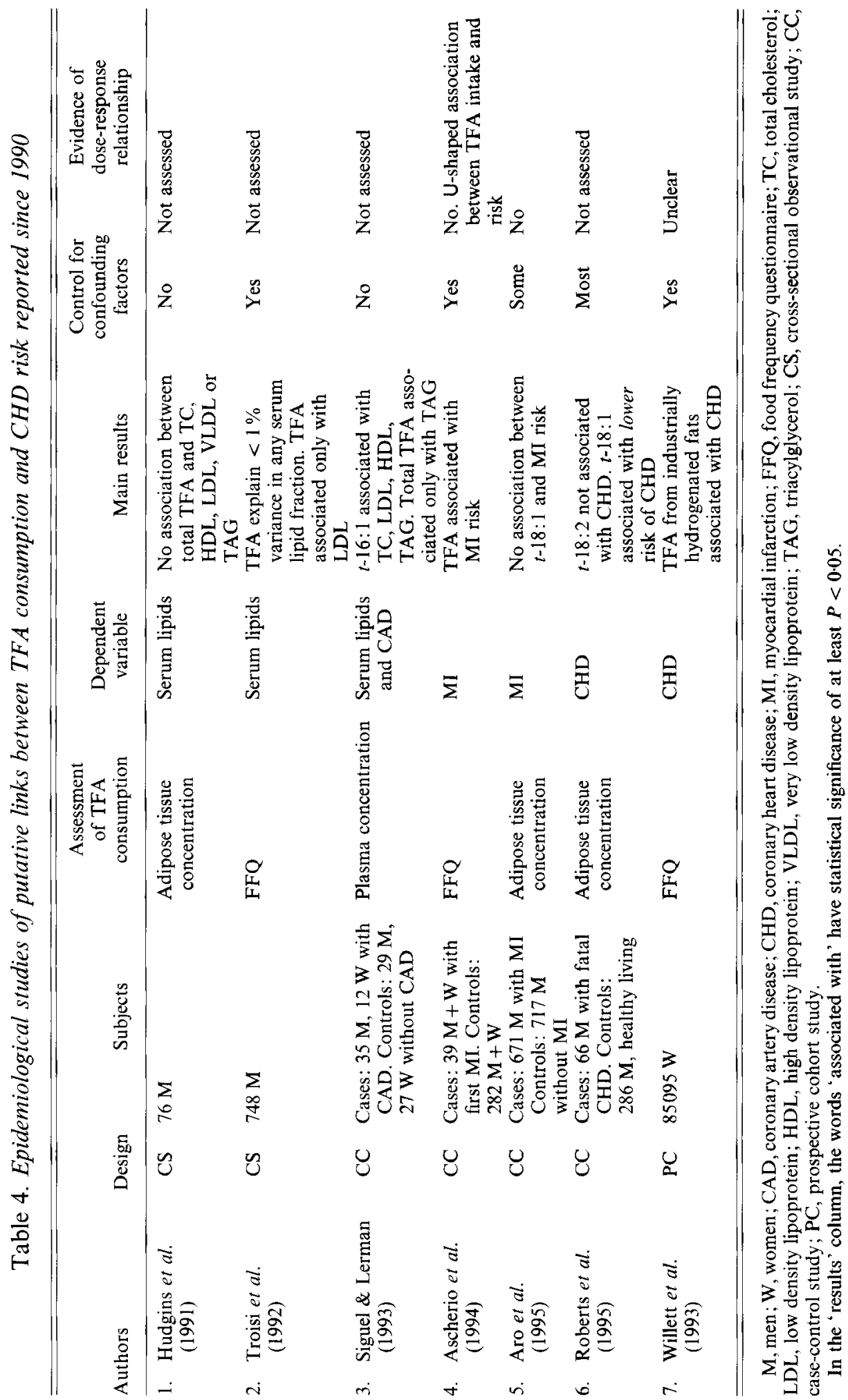


associated with the disease. This increase in risk is remarkably high when it is supposed to result from a difference of only $3 \cdot 3 \mathrm{~g} / \mathrm{d}$ between lowest and highest levels of intake. It is doubtful whether the food frequency method could discriminate sufficiently well between such close levels of intake. Furthermore, between these extremes of intake, there was no consistent dose-response relationship, since the relative risks for each quintile were: 1.00 , $1 \cdot 12,0 \cdot 99,1 \cdot 16,1 \cdot 47$.

Willett's paper implied that the difference between the results for industrially hydrogenated and ruminant fats could be explained by the activity of "the main trans isomer in industrially hydrogenated fats, elaidic acid" $(9 t-18: 1)$ and the lack of activity of "trans isomer in ruminant fat, trans-vaccenic acid" (11t-18:1). This is an inadequate characterization of the composition of the two types of fat. They contain the same isomers but in different proportions (Table 1) and it is highly unlikely that differences in content of these two isomers could explain such a large effect. Moreover, no other evidence is available to suggest that the biological effects of these two isomers are so radically different. It is prudent to consider whether the TFA content of industrially hydrogenated fats might have been acting as a marker for socioeconomic status or for other aspects of a less healthy lifestyle.

In summary, critical evaluation of epidemiological studies leads to the conclusion that an association between intakes of TFA and CHD has not been demonstrated. Nor is there any reliable information linking TFA intakes with cancer or other chronic diseases.

\section{CONCLUSIONS}

(1) There are no substantial differences, that may affect health, in digestion, absorption, transport, storage or oxidation between TFA and other fatty acids over the range of intakes normally encountered in human diets.

(2) When incorporated into lipids, the positional distribution tends to be more similar to the SFA than the corresponding cis-monounsaturates. There is no substantial evidence that this adversely influences tissue function.

(3) Most studies have been concerned with trans-MUFA with eighteen carbon atoms. More research is needed with longer chain acids derived from hydrogenation of fish oils and distinction should be made between effects due to chain length and those due specifically to double bond geometry. More research is also needed into physiological effects of unusual cis-positional isomers.

(4) Diets containing high levels of total TFA in conjunction with low intakes of linoleic acid may result in the appearance of the 'Mead acid' in tissue lipids but rarely in overt signs of EFA deficiency. More research is needed into the physiological significance of modest rises in Mead acid concentration without overt EFA deficiency. The most potent effects on EFA metabolism have been observed with trans,trans-dienoic acids which are not now significant constituents of diets.

(5) Despite firm assertions by many authors to the contrary, there is no persuasive evidence for adverse effects of TFA over the range of intakes normally encountered in human diets on plasma lipids. There may be such effects, but the design of published experiments leaves room for doubt.

(6) Despite firm assertions by many authors to the contrary, there is no persuasive evidence for adverse effects of TFA over the range of intakes normally encountered in human diets on risk of CHD or other chronic diseases.

(7) Even the best methods available in research laboratories for the separation, identification and quantitation of trans isomers are not without limitations. Some 
inconsistencies in the literature regarding the nutritional and physiological effects of TFA undoubtedly result from incorrect analysis.

These conclusions will be hotly disputed by many but seem to me to be the inevitable conclusions to be drawn from the available literature. It is of course accepted that values for average intakes conceal very high intakes (more than $12 \mathrm{~g} / \mathrm{d}$ ) by some individuals. Although the scientific evidence does not support the conclusion that even these intakes are harmful, there is bound to be uncertainty at least until there is more understanding of the biological significance of Mead acid accumulation. Likewise, although the concern expressed about the statistical association between mothers' intakes of TFA and the occurrence of low birth weight in their babies is not founded upon strong scientific evidence (Koletzko, 1992), it would be wise to investigate this potential problem further.

Regarding dietary recommendations to the public, the logical extension of the foregoing arguments is that there is no basis for specific recommendations to limit TFA. It is more important to focus on total fat intakes, which may be relevant to those desiring to control their weight and on the most appropriate ratios to be achieved between SFA, cis-MUFA and $n-3$ and $n-6$ PUFA, which may be relevant to many different aspects of health (Department of Health, 1991). In this way, intakes of TFA are unlikely to reach levels that could cause concern. Moreover, the likelihood of individuals ingesting huge amounts of TFA is decreasing as manufacturers reduce the TFA content of many products (British Nutrition Foundation, 1995; Kris-Etherton et al. 1995).

Finally, as a counterbalance to the commonly held view that 'TFA are all bad', considerable research effort is now being devoted to investigating the antioxidant and anticancer effects of 'conjugated linoleic acid', a mixture of isomers containing cis/trans dienes found mainly in products of ruminant origin (Parodi, 1994).

\section{REFERENCES}

Adlof, R. O., Copes, L. C. \& Emken, E. A. (1995). Analysis of the monoenoic fatty acid distribution in hydrogenated vegetable oils by silver-ion high-performance liquid chromatography. Journal of the American Oil Chemists' Society 72, 571-574.

Adlof, R. O. \& Emken, E. A. (1986). Distribution of hexadecenoic, octadecenoic and octadecadienoic acid isomers in human tissue lipids. Lipids 21, 543-547.

Applewhite, T. H. (1994). Trans-isomers, serum lipids and cardiovascular disease: another point of view. Nutrition Reviews 51, 344-345.

Aro, A., Kardinaal, A. F. M., Salminen, I., Kark, J. D., Riemersma, R. A., Delgado-Rodriguez, M., GomezAracena, J., Huttunen, J. K., Kohlmeier, L., Martin, B. C., Martin-Moreno, J. M., Mazaev, V. P., Ringstad, J., Thamm, M., van't Veer, P. \& Kok, F. J. (1995). Adipose tissue isomeric trans fatty acids and risk of myocardial infarction in nine countries: the EURAMIC study. Lancet 345, 273-278.

Ascherio, A., Hennekens, C. H., Buring, J. E., Master, C., Stampfer, M. J. \& Willett, W. C. (1994). Trans-fatty acids intake and risk of myocardial infarction. Circulation 89, 94-101.

Beare-Rogers, J. L. (1983). trans and positional isomers of common fatty acids. Advances in Nutrition Research 5, 171-200.

Benga, G., Travis, B. D., Pop, V. I., Popescu, O., Toader, S. \& Holmes, R. P. (1984). The effect of the saturation and isomerization of dietary fatty acids on the osmotic fragility and water diffusional permeability of rat erythrocytes. Biochimica et Biophysica Acta 775, 255-259.

Berry, E. M., Hirsch, J., Most, J., McNamara, D. J. \& Thornton, J. (1986). The relationship of dietary fat to plasma lipid levels as studied by factor analysis of adipose tissue fatty acid composition in a free-living population of middle-aged American men. American Journal of Clinical Nutrition 44, 220-231.

Beynen, A. C. \& Katan, M. B. (1989). Impact of dietary cholesterol and fatty acids on serum lipids and lipoproteins in man. In The Role of Fats in Human Nutrition, 2nd edn, pp. 237-286 [Vergroesen, A. J. \& Crawford, M., editors]. London: Academic Press.

British Nutrition Foundation (1987). Report of the Task Force on Trans Fatty Acids. London: British Nutrition Foundation.

British Nutrition Foundation (1995). Report of the Task Force on Trans Fatty Acids, 2nd edn. London: British Nutrition Foundation.

Brussaard, J. H., Katan, M. B., Groot, P. H. E., Havekes, L. M. \& Hautvast, J. G. A. J. (1982). Serum lipoproteins 
of healthy persons fed a low-fat diet or a polyunsaturated fat diet for three months: a comparison of two cholesterol-lowering diets. Atherosclerosis 42, 205-219.

Burr, G. O. \& Burr, M. M. (1929). A new deficiency disease produced by the rigid exclusion of fat from the diet. Journal of Biological Chemistry 82, 345-367.

Christie, W. W. (1995a). Trans fatty acids: the present state of the analytical methodology. Lipid Technology 7 , 113-115.

Christie, W. W. (1995b). Are methyl esters of fatty acids the best choice for gas chromatographic analysis? Lipid Technology 7, 64-66.

Cook, H. W. \& Emken, E. A. (1990). Geometric and positional fatty acid isomers interact differently with desaturation and elongation of linoleic and linolenic acids in cultured glioma cells. Biochemistry and Cell Biology 68, 653-660.

Craig-Schmidt, M. C. (1992). Fatty acid isomers in foods. In Fatty Acids in Foods and their Health Implications, pp. 365-398 [Chow, C. K., editor]. New York: Marcel Dekker.

Department of Health (1991). Dietary Reference Values for Food Energy and Nutrients for the United Kingdom. (Report on Health and Social Subjects 4I). London: HMSO.

Department of Health \& Social Security (1984). Diet and Cardiovascular Disease. (Report on Health and Social Subjects 28). London: HMSO.

Dhopeshwarkar, G. A. \& Mead, J. F. (1961). Role of oleic acid in the metabolism of essential fatty acids. Journal of the American Oil Chemists' Society 38, 297-301.

Emken, E. A. (1984). Nutrition and biochemistry of trans and positional fatty acid isomers in hydrogenated oils. Annual Review of Nutrition 4, 339-376.

Emken, E. A., Adlof, R. O., Rohwedder, W. K. \& Gulley, R. M. (1989). Incorporation of trans-8, and cis-8octadecenoic acid isomers in human plasma and lipoprotein lipids. Lipids 24, 61-69.

Emken, E. A., Dutton, H. J., Rohwedder, W. K., Rakoff, H., Adlof, R. O., Gulley, R. M. \& Canary, J. J. (1980). Distribution of deuterium labeled cis-and trans-12-octadecenoic acids in human plasma and lipoprotein lipids. Lipids 15, 864871.

Emken, E. A., Rohwedder, W. K., Adlof, R. O., DeJarlais, W. J. \& Gulley, R. M. (1986). Absorption and distribution of deuterium labeled trans- and cis-11-octadecenoic acid in human plasma and lipoprotein lipids. Lipids 21, 589-595.

Emken, E. A., Rohwedder, W. K., Adlof, R. O., Rakoff, H. \& Gulley, R. M. (1987). Metabolism in humans of cis-12, trans-15-octadecadienoic acid relative to palmitic, stearic, oleic and linoleic acids. Lipids 22, $495-504$.

Enig, M. G., Atal, S., Keeney, M. \& Sampugna, J. (1990). Isomeric trans fatty acids in the U.S. diet. Journal of the American College of Nutrition 9, 471-486.

Federation of American Societies for Experimental Biology (1985). Health Aspects of Dietary Trans Fatty Acids. Bethesda: FASEB.

Fehily, A. M., Yarnell, J. W. G., Bolton, C. H. \& Butland, B. K. (1988). Dietary determinants of plasma lipids and lipoproteins: The Caerphilly Study. European Journal of Clinical Nutrition 42, 405-413.

Fehily, A. M., Yarnell, J. W. G., Sweetnam, P. M. \& Elwood, P. C. (1993). Diet and incident ischaemic heart disease: the Caerphilly Study. British Journal of Nutrition 69, 303-314.

Firestone, D. \& Sheppard, A. (1992). Determination of trans fatty acids. In Advances in Lipid Methodology-One, pp. 273-322 (W. W. Christie, editor). Ayr: Oily Press.

Gregory, J., Foster, K., Tyler, H. \& Wiseman, M. J. (1990). The Dietary and Nutritional Survey of British Adults. London: HMSO.

Grundy, S. M. \& Denke, M. A. (1990). Dietary influences on serum lipids and lipoproteins. Journal of Lipid Research 31, 1149-1172.

Gunstone, F. D., Harwood, J. L. \& Padley, F. B. (editors). (1994). The Lipid Handbook, 2nd edn. London: Chapman \& Hall.

Gurr, M. I. (1983). Trans fatty acids: metabolic and nutritional significance. International Dairy Federation Bulletin, Document 166, pp. 5-18. Brussels: International Dairy Federation.

Gurr, M. I. (1992). Dietary lipids and coronary heart disease: old evidence, new perspective. Progress in Lipid Research 31, 195-243.

Gurr, M. I., Borlak, N. \& Ganatra, S. (1989). Dietary fat and plasma lipids. Nutrition Research Reviews 2, 63-86.

Gurr, M. I. \& Harwood, J. L. (1992). Lipid Biochemistry: an introduction, 4th edn. London: Chapman \& Hall.

Hegsted, D. M., Ausman, L. M., Johnson, J. A. \& Dallal, G. E. (1993). Dietary fat and serum lipids: an evaluation of the experimental data. American Journal of Clinical Nutrition 57, 875-883.

Hill, E. G., Johnson, S. B. \& Holman, R. T. (1979). Intensification of essential fatty acid deficiency in the rat by dietary trans fatty acids. Journal of Nutrition 109, 1759-1765.

Holman, R. T. (1985). Influence of hydrogenated fats on the metabolism of polyunsaturated fatty acids. In The Role of Fats in Human Nutrition, pp. 48-61 [Padley, F. B. \& Podmore, J. editors]. Chichester: Ellis Horwood.

Hudgins, L. C., Hirsch, J. \& Emken, E. A. (1991). Correlation of isomeric fatty acids in human adipose tissue with clinical risk factors for cardiovascular disease. American Journal of Clinical Nutrition 53, 474482.

Hunter, J. E. \& Applewhite, T. H. (1991). Reassessment of trans fatty acid availability in the US diet. American Journal of Clinical Nutrition 54, 363-369.

Hwang, D. H. \& Kinsella, J. E. (1979). The effects of trans,trans-methyl linoleate on the concentration of prostaglandins and their precursors in rats. Prostaglandins 17, 543-558. 
Judd, J. T., Clevidence, B. A., Muesing, R. A., Wittes, J., Sunkin, M. E. \& Podczasy, J. J. (1994). Dietary trans fatty acids: effects on plasma lipids and lipoproteins of healthy men and women. American Journal of Clinical Nutrition 59, 861-868.

Katan, M. B., van Staveren, W. A., Deurenberg, P., Barendse-Van Leeuwen, J., Germing-Nouwen, C., Soffers, A., Berkel, J. \& Beynen, A. C. (1986). Linoleic and trans-unsaturated fatty acid content of adipose tissue biopsies as objective indicators of the dietary habits of individuals. Progress in Lipid Research 25, $193-195$.

Koletzko, B. (1992). Trans fatty acids may impair biosynthesis of long-chain polyunsaturates and growth in man. Acta Paediatrica 81, 302-306.

Kris-Etherton, P. M., Allison, D. B., Denke, M. A., Dietschy, J. M., Emken, E. A. \& Nicolosi, R. J. (1995). Trans fatty acids and coronary heart disease risk. American Journal of Clinical Nutrition 62, 655S-708S.

Kritchevsky, D. (1983). Trans fatty acid effects in experimental atherosclerosis. Federation Proceedings 41, 2813-2817

Lichtenstein, A. H., Ausman, L. M., Carrasco, W., Jenner, J. L., Ordovas, J. M. \& Schaefer, E. J. (1993). Hydrogenation impairs the hypolipidemic effect of corn oil in humans: hydrogenation, trans fatty acids, and plasma lipids. Arteriosclerosis and Thrombosis 13, 154-161.

Mensink, R. P. \& Katan, M. B. (1990). Effects of dietary trans fatty acids on high density and low density lipoprotein cholesterol levels in healthy subjects. New England Journal of Medicine 323, 439-444.

Mensink, R. P., Zock, P. L., Katan, M. B. \& Hornstra, G. (1992). Effect of dietary cis and trans fatty acids on serum lipoprotein [a] levels in humans. Journal of Lipid Research 33, 1493-1501.

Moore, C. E., Alfin-Slater, R. B. \& Aftergood, L. (1980). Incorporation and disappearance of trans fatty acids in rat tissues. American Journal of Clinical Nutrition 22, 2318-2323.

Mossoba, M. M., McDonald, R. E. \& Prosser, A. R. (1993). Gas chromatography/matrix isolation/Fourier transform infrared spectroscopic determination of trans-monounsaturated and saturated fatty acid methyl esters in partially hydrogenated menhaden oil. Journal of Agricultural and Food Chemistry 41, $1998-2002$.

Nelson, G. J., Schmidt, P. C. \& Kelley, D. S. (1995). Low-fat diets do not lower plasma cholesterol levels in healthy men compared to high-fat diets with similar fatty acid composition at constant caloric intake. Lipids 30, 969-976.

Nestel, P., Noakes, M., Belling, B., McArthur, R., Clifton, P., Janus, E. \& Abbey, M. (1992). Plasma lipoprotein lipid and Lp [a] changes with substitution of elaidic acid for oleic acid in the diet. Journal of Lipid Research $\mathbf{3 3}$ $1029-1036$.

Parodi, P. W. (1976a). Distribution of isomeric octadecenoic fatty acids in milk fat. Joumal of Dairy Science 59, 1870-1873.

Parodi, P. W. (1976 b). Composition and structure of some consumer available edible fats. Journal of the American Oil Chemists' Society 53, 530-534.

Parodi, P. W. (1994). Conjugated linoleic acid: an anticarcinogenic fatty acid present in milk fat. Australian Journal of Dairy Technology 49, 93-97.

Ratnayake, W. M. N., Chen, Z. Y., Pelletier, G. \& Weber, D. (1994). Occurrence of $5 c, 8 c, 11 c, 15 t$-eicosatetraenoic acid and other unusual polyunsaturated fatty acids in rats fed partially hydrogenated canola oil. Lipids 29 , 707-714.

Ratnayake, W. M. N., Hollywood, R., O'Grady, E. \& Beare-Rogers, J. L. (1990). Determination of cis and transoctadecenoic acids in margarines by gas liquid chromatography-infrared spectrophotometry. Journal of the American Oil Chemists' Society 67, 804-810.

Reddy, S., Sanders, T. A. \& Obeid, O. (1994). The influence of maternal vegetarian diet on essential fatty acid status of the newborn. European Journal of Clinical Nutrition 48, 358-368.

Roberts, T. L., Wood, D. A., Riemersma, R. A., Gallagher, P. J. \& Lampe, F. C. (1995). Trans isomers of oleic and linoleic acids in adipose tissue and sudden cardiac death. Lancet 345, 278-282.

Rosenthal, M. D. \& Whitehurst, M. C. (1983). Selective effects of isomeric cis and trans fatty acids on fatty acyl $\delta 9$ and $\delta 6$ desaturation by human skin fibroblasts. Biochimica et Biophysica Acta 753, 450 459.

Seelig, J. \& Waespe-Šarčevic̀, N. (1978). Molecular order in cis and trans unsaturated phospholipid bilayers. Biochemistry 17, 3310-3315.

Siguel, E. N. \& Lerman, R. H. (1993). Trans-fatty acid patterns in patients with angiographically documented coronary artery disease. American Journal of Cardiology 71, 916-920.

Stender, S., Dyerberg, J., Holmer, G., Ovesen, L. \& Sandstrom, B. (1995). The influence of trans fatty acids on health: a report from the Danish Nutrition Council. Clinical Science 88, 375-392.

Toschi, T. G., Capella, P., Holt, C. \& Christie, W. W. (1993). A comparison of silver ion HPLC plus GC with Fourier-transform IR spectroscopy for the determination of trans double bonds in unsaturated fatty acids. Journal of the Science of Food and Agriculture 61, 261-266.

Troisi, R., Willett, W. C. \& Weiss, S. T. (1992). Trans-fatty acid intake in relation to serum lipid concentrations in adult men. American Journal of Clinical Nutrition 56, 1019-1024.

Wahle, K. W. J. \& James, W. P. T. (1993). Isomeric fatty acids and human health. Review. European Journal of Clinical Nutrition 47, 828-839.

Willett, W. C., Stampfer, M. J., Manson, J. E., Colditz, G. A., Speizer, F. E., Rosner, B. A., Sampson, L. A. \& Hennekens, C. H. (1993). Intake of trans fatty acids and risk of coronary heart disease among women. Lancet 341, 581-585 
Wood, R. (1979). Incorporation of dietary cis and trans octadecenoate isomeres in the lipid classes of various rat tissues. Lipids 14, 975-982.

Wood, R., Kubena, K., O'Brien, B., Tseng, S. \& Martin, G. (1993). Effect of butter, mono- and polyunsaturated fatty acid-enriched butter, trans fatty acid margarine, and zero trans fatty acid margarine on serum lipids and lipoproteins in healthy men. Journal of Lipid Research 34, 1-11.

Woollett, L. A., Daumerie, C. M. \& Dietschy, J. M. (1994). Trans-9-octadecenoic acid is biologically neutral and does not regulate the low density lipoprotein receptor as the cis isomer does in the hamster. Journal of Lipid Research 35, 1661-1673.

Zevenbergen, J. L. \& Haddeman, E. (1989). Lack of effects of trans fatty acids on eicosanoid biosynthesis with adequate intakes of linoleic acid. Lipids 24, 555-563.

Zevenbergen, J. L., Houtsmuller, U. M. T. \& Gottenbos, J. J. (1988). Linoleic acid requirement of rats fed trans fatty acids. Lipids 23, 178-186.

Zock, P. L. \& Katan, M. B. (1992). Hydrogenation alternatives: effects of trans fatty acids and stearic acid versus linoleic acid on serum lipids and lipoproteins in humans. Journal of Lipid Research 33, 399-410. 